IP $\rightleftharpoons$ B

\title{
Sobrevivência de plântulas de espécies florestais nativas, em mata ciliar no estado de Sergipe
}

\author{
Janisson Batista de Jesus ${ }^{1 *}\left(\mathbb{D}\right.$, Robério Anastácio Ferreira2 ${ }^{(\mathbb{D}}$, Dráuzio Correia Gama ${ }^{3(\mathbb{D}}$, Alisson Marcel Souza de Oliveira ${ }^{4}(\mathbb{D})$ \\ ${ }^{1}$ Universidade Federal do Rio Grande do Sul, Campus Vale, Avenida Bento Gonçalves, 9500, Prédio 44202, Setor 5, CEP $91501-970$, Porto Alegre, RS, Brasil \\ ${ }^{2}$ Universidade Federal de Sergipe, Departamento de Ciências Florestais, Avenida Marechal Rondon, s/n, Jd. Rosa Elze, CEP 49100-000, São Cristóvão, SE, Brasil \\ ${ }^{3}$ Universidade Estadual do Sudoeste da Bahia, km 04, CEP 45031-900, Vitória da Conquista, BA, Brasil \\ ${ }^{4}$ Universidade Federal de Sergipe, Campus do Sertão, Rodovia Engenheiro Jorge Neto, km 03, Silos, CEP 49680-000, Nossa Senhora da Glória, SE, Brasil
}

"Autor correspondente:

janisson-batista-de-jesus@hotmail.com

Termos para indexação:

Degradação ambiental

Dormência de semente

Semente florestal

Index terms:

Environmental degradation

Seed dormancy

Forest seed

Histórico do artigo:

Recebido em 19/09/2018

Aprovado em 31/10/2019

Publicado em 09/01/2020
Resumo - Esse estudo foi realizado com o objetivo de analisar o comportamento temporal da sobrevivência de plântulas de espécies florestais nativas, visando à recuperação da vegetação ciliar de dois trechos do Rio Piauitinga, no município de Lagarto, estado de Sergipe. Em campo, o delineamento da semeadura direta se deu em blocos casualizados, testando 5 espécies nativas (2 pioneiras: Guazuma ulmifolia Lam. e Cecropia pachystachya Trécul. e 3 clímax exigentes em luz: Cassia grandis L.f., Enterolobium contortisiliquum (Vell.) e Libidibia ferrea var. leiostachya L. P. Queiroz), utilizando 2 tratamentos (sem e com a aplicação de tratamento para a superação de dormência), em quatro repetições amostrais. Plântulas de $E$. contortisiliquum originárias de sementes sem quebra de dormência se destacaram, tendo a maior sobrevivência entre as espécies e tratamentos utilizados. L. ferrea var. leiostachya apresentou emergência tardia. A sobrevivência inicial das plântulas das espécies utilizadas nos trechos de mata ciliar do Rio Piauitinga apresentou decréscimo ao passar do tempo, até atingir a estabilização da mortalidade, independente das sementes receberem ou não tratamento para a superação de dormência.

\section{Survival of native forest seedlings in riparian forest at Sergipe State, Brazil}

\begin{abstract}
The objective of this study was to analyze the temporal behavior of seedlings survival from seeds without and with the application of treatment to overcome dormancy. We used native forest species, in a riparian forest area of the Piauitinga River, at the municipality of Lagarto, Sergipe State, Brazil. In the field, the design of the direct sowing was in randomized blocks, testing 5 native species (2 pioneer: Guazuma ulmifolia Lam. e Cecropia pachystachya Trécul. and 3 climax species, that are demanding of light: Cassia grandis L.f., Enterolobium contortisiliquum (Vell.) and Libidibia ferrea var. leiostachya L. P. Queiroz). We used 2 treatments (without and with the application of treatment to overcome dormancy) in four replicate samples. Seedlings of Enterolobium contortisiliquum from seeds without treatment to overcome dormancy presented the highest survival among the species and treatments used. Libidibia ferrea var. leiostachya presented late emergence. The initial survival of the species seedlings used in the riparian forest sections of the Piauitinga River showed a decrease over time until stabilization was achieved after sowing, regardless treatment to overcome dormancy.
\end{abstract}




\section{Introdução}

As matas ciliares são definidas pela legislação brasileira como áreas de preservação permanente. Caso estejam degradadas, principalmente em decorrência de atividades de origem antrópica, devem ser restauradas e mantidas sob proteção (Costa et al., 2010).

Diante do estado de degradação no qual estes ecossistemas naturais se encontram, tem-se notado a ampliação das atividades de restauração destas áreas ao passar dos tempos, sendo cada vez mais aplicada (Silva et al., 2015). Destaca-se que, parte do sucesso da recuperação/restauração está associado à forma em que as espécies florestais são introduzidas, levando-se em consideração o conhecimento sobre o comportamento das espécies nas diferentes condições abióticas, a fim de se obter as melhores respostas da capacidade de sobrevivência e estabelecimento em campo (Lima et al., 2014).

A semeadura direta de espécies florestais é, ultimamente, uma das técnicas mais indicadas nos programas de restauração de áreas com baixa capacidade de regeneração natural. Em Sergipe, alguns trabalhos já norteiam a aplicação da técnica da semeadura utilizando espécies florestais nativas em atividades de recomposição de áreas degradadas e da mata ciliar (Ferreira et al., 2009; Santos et al., 2012; Jesus et al., 2017). Apesar disto, ainda existem poucos estudos desenvolvidos sobre a temática, não trazendo à tona da área científica a vasta gama de conhecimento pertinente ao assunto (Cava et al., 2016). Um exemplo é ausência de informações sobre o sucesso da emergência e sobrevivência das plântulas em campo, quanto ao uso de tratamentos pré-germinativos para superar a dormência das sementes de espécies florestais nas atividades de restauração (Pereira et al., 2013).

No processo de recuperação florestal em ecossistemas tropicais, também é fundamental compreender a forma com que as espécies respondem aos fatores abióticos, entre eles temperatura e disponibilidade de água, que afetam o estabelecimento, desenvolvimento e a sobrevivência de plântulas. Isto possibilita o entendimento da interação entre as plântulas e o ambiente, permitindo criar teorias relacionadas à dinâmica de populações e comunidades florestais aplicáveis às atividades de sucessão florestal (Turchetto et al., 2015). Do mesmo modo, é importante que sejam avaliados fatores relacionados aos solos da área a ser estudada em trabalhos de recuperação florestal (Azevêdo et al., 2012).
Portanto, este estudo foi realizado com o objetivo de analisar o comportamento temporal da sobrevivência de plântulas de espécies florestais nativas, provenientes de sementes sem e com a aplicação de tratamento para a superação de dormência, em área de mata ciliar do Rio Piauitinga, município de Lagarto, Sergipe.

\section{Material e métodos}

\section{Caracterização da área de estudo}

Foram selecionados para o estudo dois trechos da mata ciliar do Rio Piauitinga, cada um de um lado da margem, distantes entre si cerca de $300 \mathrm{~m}$, em áreas degradadas por pastagem e agricultura. O local faz parte da unidade de planejamento do Rio Piauitinga, situado especificamente no povoado Brasília, município de Lagarto, SE, sob as coordenadas UTM E 657.800; N 8.793.400 e E 658.000; N 8.793.200, fuso 24 S.

$\mathrm{Na}$ região, os meses de maio a julho são os mais chuvosos, com clima caracterizado como "As", segundo a classificação de Köppen (Lundgren et al., 2017), com precipitação média anual de $1.000 \mathrm{~mm}$, e as menores temperaturas mínimas médias do ar ocorrendo em julho e agosto (Sousa et al., 2010). O solo típico no local de estudo da sub-bacia hidrográfica é o Latossolo Vermelho Amarelo (Sergipe, 2011).

\section{Seleção e tratamento das sementes utilizadas}

As espécies selecionadas foram baseadas nos grupos ecológicos, sendo definidas como pioneiras com sementes dormentes: Guazuma ulmifolia Lam. e Cecropia pachystachya Trécul, e as clímax exigentes em luz: Cassia grandis L.f., Enterolobium contortisiliquum (Vell.) e Libidibia ferrea var. leiostachya L. P. Queiroz, classificadas de acordo com o grupo ecológico indicado por Oliveira-Filho et al. (1995). A escolha destas espécies foi definida com base na sua ocorrência natural nas matas ciliares da sub-bacia hidrográfica do Rio Piauitinga, e em conciliação com a disponibilidade das sementes na câmara fria do Departamento de Ciências Florestais da Universidade Federal de Sergipe (UFS).

Os frutos das espécies utilizadas no presente estudo foram coletados em árvores-matrizes da região, transportados em sacos de polietileno trançado e depositados no viveiro florestal da UFS, para o seu posterior beneficiamento. Em seguida, as sementes 
foram secas à sombra e devidamente armazenadas em câmara fria no Departamento de Ciências Florestais, a temperaturas de $6^{\circ}-9^{\circ} \mathrm{C}$ e $60-65 \%$ de umidade relativa do ar, permanecendo nesta condição até o uso para o estudo.

Foram utilizadas sementes com e sem tratamento para a superação da dormência, o que corresponde aos tratamentos empregados. A superação da dormência das sementes foi realizada conforme Jesus et al. (2019), por meio da escarificação química com ácido sulfúrico concentrado, de 30 a 50 min de imersão, com exceção de Cecropia pachystachya, que foi embebida em água destilada por $1 \mathrm{~h}$. Após a imersão, as sementes tratadas com ácido foram lavadas em água destilada por $10 \mathrm{~min}$. Os procedimentos para o tratamento para superação da dormência das sementes foram realizados no Laboratório de Sementes da UFS.

\section{Implantação e condução do experimento em campo}

$\mathrm{O}$ experimento foi implantado no dia 02 de julho de 2014. A área foi isolada para o plantio, com cercas de arame farpado, sendo realizada roçada manual. O delineamento em campo se deu através de blocos casualisados, considerando-se 2 tratamentos (com e sem dormência) e 5 espécies nativas, em 4 repetições, com 10 covas cada, no espaçamento de 2,0 x 1,0 m, totalizando 400 covas em toda a área de estudo. Foi realizado coroamento em um raio de $50 \mathrm{~cm}$ ao redor de cada cova. Para a semeadura, foram utilizadas duas densidades, com 20 sementes/cova para Libidibia ferrea var. leiostachya e 10 para as demais espécies, levando-se em consideração os resultados dos testes de germinação em laboratório, onde se observou a qualidade inicial dos lotes, de acordo com a Regras para Análise de Sementes (Brasil, 2009). Também foram utilizadas duas profundidades de semeadura, uma vez que se tratam de sementes com diferentes tamanhos, objetivandose maior eficiência de emergência para cada espécie, sendo 1,0 cm para Cecropia pachystachya e Guazuma ulmifolia, e 1,5 cm para as sementes de Cassia grandis, Enterolobium contortisiliquum e Libidibia ferrea var. leiostachya.

Foi realizada adubação aos 30 dias após a semeadura com $200 \mathrm{~g}$ de superfosfato simples e aos 60 dias, utilizando-se $150 \mathrm{~g}$ de NPK 20:10:20. Os produtos foram incorporados ao solo através de pequenas covas distante $15 \mathrm{~cm}$ do local da semeadura. Quando necessário, também foi realizado o uso de iscas formicidas granuladas na área, para o controle de formigas cortadeiras.

\section{Avaliações em campo e análises estatísticas}

A sobrevivência das plântulas foi avaliada pelo número médio de indivíduos vivos, contabilizado semanalmente até três meses após a semeadura, totalizando 12 leituras. Considerou-se também o número de plântulas emergidas (as que apresentaram os protófilos visíveis) em função da quantidade de sementes semeadas, para cada espécie em cada período de análise, para verificar o recrutamento dos indivíduos. Os dados foram transformados pelo arco-seno da $\sqrt{ }(\mathrm{x} / 100)$ do número de indivíduos. As médias de cada espécie, em cada tratamento, foram submetidas à análise de variância, sendo analisadas no programa estatístico Sisvar (Ferreira, 2014). As médias significativas foram comparadas pelo teste de Tukey a $5 \%$.

A precipitação diária, obtida na estação meteorológica mais próxima (município de Boquim, $\mathrm{SE}$ ), a temperatura e a umidade do solo foram avaliadas ao longo do período de estudo. Foram realizadas medidas em três pontos (base $=$ próximo ao rio, médio $=$ distância mediana entre a base e o topo, e topo $=$ ponto mais afastado do curso d'água) ao longo do perfil de cada bloco de tratamento. Os dados de temperatura do solo foram obtidos nas profundidades de 5 e $10 \mathrm{~cm}$, utilizando-se o geotermômetro Gulterm 180. A umidade do solo foi determinada utilizando-se amostras coletadas a $10 \mathrm{~cm}$ de profundidade. Essas amostras foram, posteriormente, pesadas e secas em estufas com circulação de ar forçada a $105^{\circ} \mathrm{C}$ por $24 \mathrm{~h}$ na UFS. A determinação da umidade foi realizada conforme Claessen (1997). Os dados de temperatura e umidade do solo foram obtidos semanalmente a partir de medidas únicas.

\section{Resultados}

Analisando-se o regime pluviométrico diário da região, observou-se que o mês de julho foi o que apresentou maior acúmulo mensal $(266,75 \mathrm{~mm})$, em comparação com os meses de agosto $(75,5 \mathrm{~mm})$ e setembro (51,5 mm). Quanto ao mês de julho, destacase também a grande quantidade de chuva incidente no dia $16(135,5 \mathrm{~mm})$, o que caracteriza um forte evento de precipitação na área. Setembro foi o mês que apresentou os menores valores acumulados, com destaque à ausência de chuvas no início e final do mês (Figura 1). 
Como consequência das características pluviométricas e da proximidade do rio, a umidade e a temperatura do solo variaram ao longo do tempo analisado. Observou-se que a umidade apresentou maiores valores no início das análises, e foi reduzindo gradativamente ao final da série. A temperatura foi similar para ambas as profundidades, mas aumentou substancialmente ao passar o período de estudo, conforme a redução do regime das precipitações, com destaque à profundidade de $5 \mathrm{~cm}$ que apresentou temperaturas mais elevadas (Figura 2). Quanto à distância das plântulas em relação ao rio, em geral, a base (ponto mais próximo ao leito do curso d'água) apresentou as menores temperaturas em ambas as profundidades avaliadas, e maiores teores de água, com uma resposta inversa, no topo do terreno, e valores intermediários no ponto médio do perfil analisado.

Figura 1. Precipitação diária $(\mathrm{mm})$ durante os meses de estudo obtidos da estação meteorológica de Boquim, SE.

Figure 1. Daily precipitation $(\mathrm{mm})$ during the study months obtained from the Boquim,Sergipe State meteorological station.
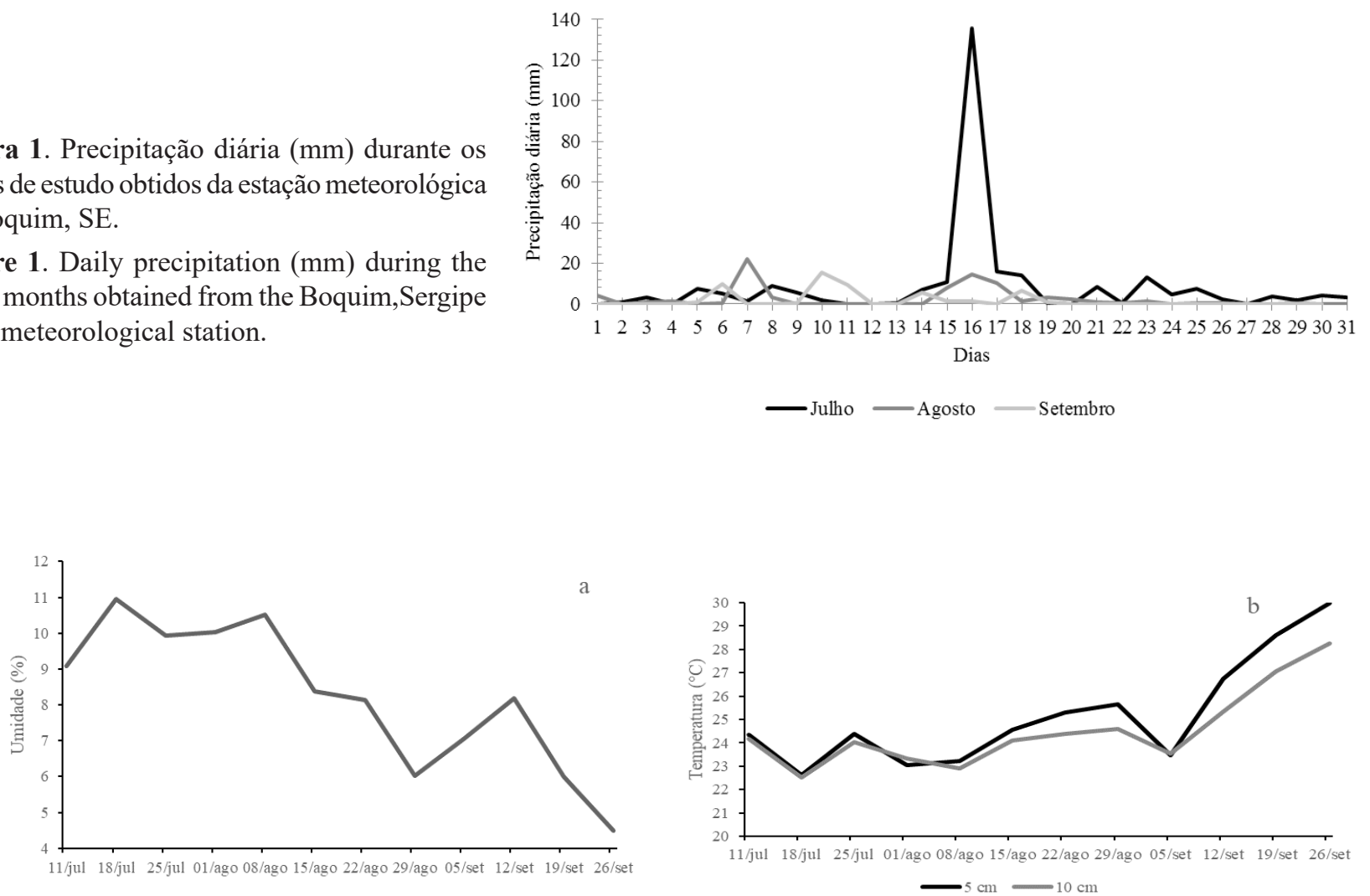

Figura 2. Valores médios de umidade $(\%)$ de $0-10 \mathrm{~cm}$ de profundidade (a), e temperatura do solo $\left({ }^{\circ} \mathrm{C}\right)$ a $5(\mathrm{~T} 5 \mathrm{~cm})$ e $10 \mathrm{~cm}(\mathrm{~T} 10 \mathrm{~cm})$ de profundidade (b), ao longo dos 90 dias do estudo na área de mata ciliar do rio Piauitinga, município de Lagarto, SE.

Figure 2. Average values of moisture (\%) of $0-10 \mathrm{~cm}$ of depth (a), and soil temperature $\left({ }^{\circ} \mathrm{C}\right)$ to $5(\mathrm{~T} 5 \mathrm{~cm})$ and $10 \mathrm{~cm}$ $(\mathrm{T} 10 \mathrm{~cm}$ ) of depth (b), along the 90 days of the study in the riparian forest area of the Piauitinga river, municipality of Lagarto, Sergipe State.

Ao longo dos 90 dias do estudo, a umidade e a temperatura do solo foram influenciadas pelo alto índice pluviométrico verificado no dia 16 do mês de julho (Figura 1), onde se observou os maiores valores de umidade e menores temperaturas, tanto a 5 como 10 $\mathrm{cm}$ de profundidade (Figura 2), em todos os blocos para todos os pontos de coleta de dados.
Observa-se que existe um padrão da sobrevivência das plântulas ao longo do tempo, tanto daquelas provenientes de sementes sem tratamento para a superação de dormência quanto daquelas que o receberam, onde inicialmente há maiores valores de plântulas contabilizadas que se reduz ao fim da série analisada (Figura 3). A única exceção foi Libidibia ferrea 
var. leiostachya, uma vez que esta espécie apresentou maior emergência de plântulas provenientes de sementes sem tratamento para a superação da dormência da metade para o final da série estudada, com alta sobrevivência dos
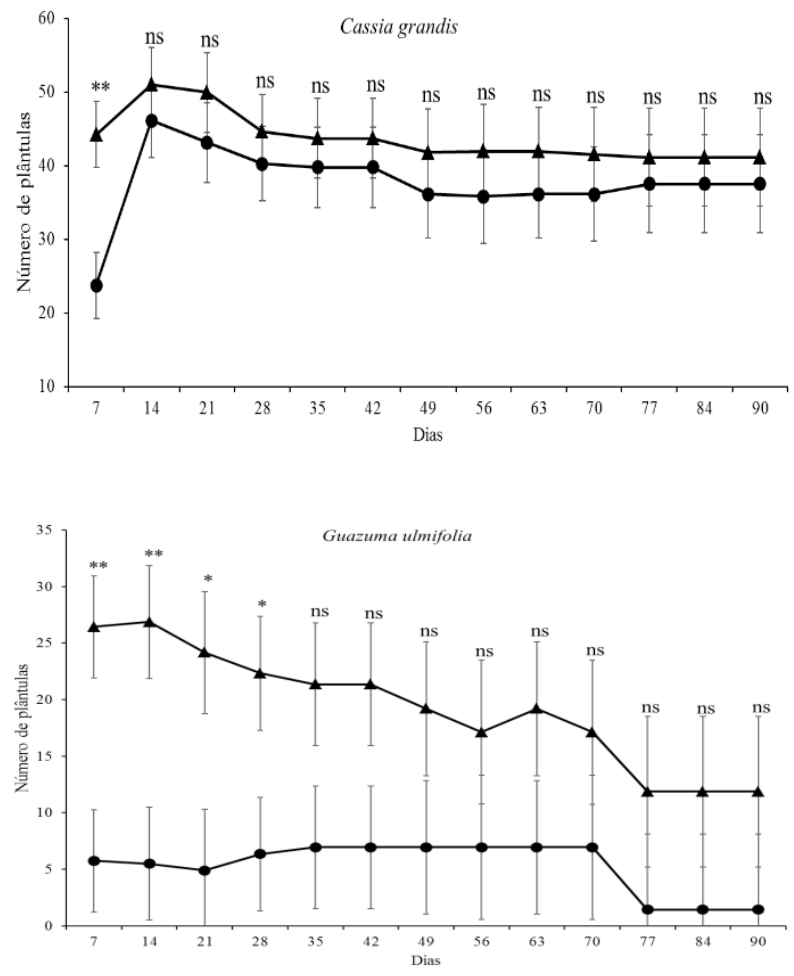

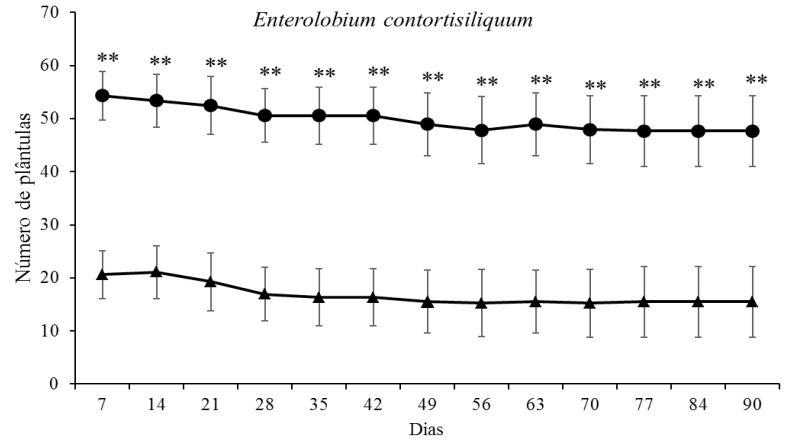

indivíduos ao final dos 90 dias. As sementes de Cecropia pachystachya não tiveram emergência em ambos os tratamentos, não tendo plântulas contabilizadas.

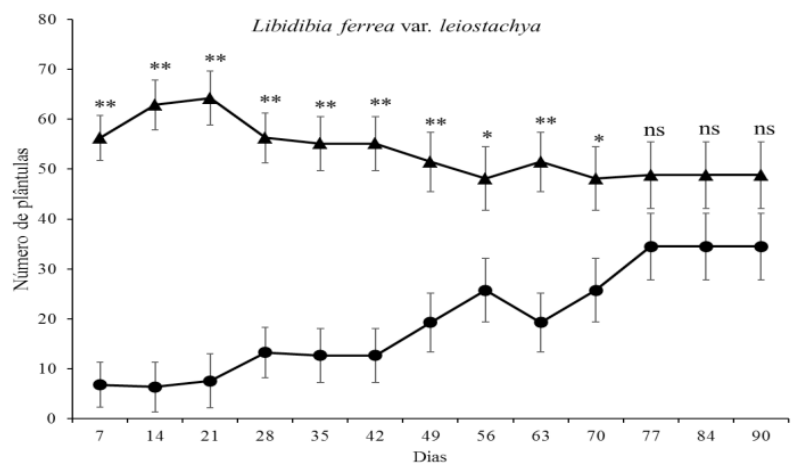

$\rightarrow \mathrm{CD} \leftarrow \mathrm{SD}$

Figura 3. Média da sobrevivência das espécies estudadas ao longo do estabelecimento das plântulas (90 dias) provenientes de sementes com (CD) e sem dormência (SD) de mata ciliar do rio Piauitinga, município de Lagarto, SE. Barras representam o erro-padrão, ${ }^{* *} \mathrm{e} *$ = significativo a $1 \%$ e $5 \%$, respectivamente; ns = não significativo.

Figure 3. Mean of the survival of the species studied along the seedlings establishment (90 days) from seeds with (CD) and without dormancy (SD) of riparian forest of the Piauitinga river, municipality of Lagarto, Sergipe State. Bars represent the standard error, $* *$ and $*=$ significant at $1 \%$ and $5 \%$, respectively; ns $=$ not significant.

Resposta semelhante a L. ferrea var. leiostachya foi verificada em Guazuma ulmifolia, porém com semelhança estatística entre os tratamentos apenas a partir dos 35 dias após a semeadura. C. grandis também apresentou um comportamento típico de maior sobrevivência no início do período analisado logo a partir da segunda semana de avaliação e se mantendo até os 90 dias, mas sem diferença entre as plântulas provenientes de sementes com e sem tratamento para quebrar de dormência. A sobrevivência de plantas de Enterolobium contortisiliquum provenientes de sementes intactas ou escarificadas diferiu significativamente ao longo de todo período experimental, sendo a espécie que manteve a maior uniformidade na quantidade de plântulas sobreviventes.

O maior número de indivíduos emergidos foi verificado nas sementes de L. ferrea var. leiostachya, Cassia grandis e G. ulmifolia quando submetidas a tratamento para a superação de dormência, o que não foi observado para E. contorsiliquum.

Observou-se a presença de muitos indivíduos resultante dos valores da emergência até a segunda avaliação. Aos 14 dias pós-semeadura, nota-se uma média semelhante de sobrevivência entre as espécies 
para a primeira época de monitoramento, com aumento para algumas espécies como verificado em $C$. grandis em ambos os tratamentos, e L. ferrea var. leiostachya (SD). Após este período, comparando-se a média da sobrevivência das espécies por período de avaliação para as plântulas provenientes de sementes dormentes, verifica-se que houve semelhança estatística entre $C$. grandis e E. contortisiliquum até os 90 dias, com $L$. ferrea var. leiostachya se destacando entre as espécies estudadas, mostrando os mais altos valores de médias ao final da série, tendo semelhança estatística apenas com $C$. grandis, valores significativos de sobrevivência (Tabela 1).

Tabela 1. Médias da sobrevivência das plântulas das espécies estudadas, provenientes de sementes com dormência (CD) e sem dormência (SD), para cada período de avaliação ao longo dos 90 dias de estabelecimento, na área de mata ciliar do rio Piauitinga, município de Lagarto, estado de Sergipe.

Table 1. Means of survival of seedlings of the species studied from seeds with dormancy (CD) and without dormancy (SD) for each evaluation period during the 90 days of establishment, in the riparian forest area of the Piauitinga river, in the municipality of Lagarto, Sergipe State.

\begin{tabular}{|c|c|c|c|c|c|c|c|c|}
\hline \multirow{2}{*}{ Dias } & \multicolumn{4}{|c|}{ CD } & \multicolumn{4}{|c|}{ SD } \\
\hline & $\mathrm{Cg}$ & Ec & Gu & Lf & $\mathrm{Cg}$ & Ec & Gu & Lf \\
\hline 7 & $23,76 \mathrm{~b}$ & $54,03 \mathrm{a}$ & $5,73 \mathrm{c}$ & $6,77 \mathrm{bc}$ & $44,28 \mathrm{ab}$ & $20,62 \mathrm{c}$ & $26,43 \mathrm{bc}$ & $56,30 \mathrm{a}$ \\
\hline 14 & 46,15 a & $53,38 \mathrm{a}$ & $5,50 \mathrm{~b}$ & $6,32 \mathrm{~b}$ & $51,08 \mathrm{a}$ & $21,01 \mathrm{~b}$ & $26,87 \mathrm{~b}$ & $62,89 a$ \\
\hline 21 & 43,18 a & $52,46 \mathrm{a}$ & $4,90 \mathrm{~b}$ & $7,56 \mathrm{~b}$ & $50,00 \mathrm{a}$ & $19,25 \mathrm{~b}$ & $24,17 \mathrm{~b}$ & $64,22 \mathrm{a}$ \\
\hline 28 & $40,31 \mathrm{a}$ & $50,53 \mathrm{a}$ & $6,33 \mathrm{~b}$ & $13,23 \mathrm{~b}$ & 44,66 a & $16,92 \mathrm{~b}$ & $22,32 \mathrm{~b}$ & $56,26 \mathrm{a}$ \\
\hline 35 & $39,80 \mathrm{a}$ & $50,53 \mathrm{a}$ & $6,93 \mathrm{~b}$ & $12,64 \mathrm{~b}$ & $43,74 \mathrm{a}$ & $16,32 \mathrm{~b}$ & $21,36 \mathrm{~b}$ & 55,16 a \\
\hline 42 & $39,80 \mathrm{a}$ & $50,53 \mathrm{a}$ & $6,93 \mathrm{~b}$ & $12,64 \mathrm{~b}$ & $43,74 \mathrm{a}$ & $16,32 \mathrm{~b}$ & $21,36 \mathrm{~b}$ & 55,16 a \\
\hline 49 & $36,17 \mathrm{ab}$ & $48,95 \mathrm{a}$ & $6,93 \mathrm{c}$ & $19,26 \mathrm{bc}$ & $41,85 \mathrm{ab}$ & $15,52 \mathrm{c}$ & $19,20 \mathrm{bc}$ & $51,45 a$ \\
\hline 56 & 35,87 a & $47,80 \mathrm{a}$ & $6,93 \mathrm{~b}$ & $25,72 \mathrm{ab}$ & $41,99 \mathrm{ab}$ & $15,23 \mathrm{c}$ & $17,12 \mathrm{bc}$ & $48,12 \mathrm{a}$ \\
\hline 63 & $36,17 \mathrm{ab}$ & $48,95 \mathrm{a}$ & $6,93 \mathrm{c}$ & $19,26 \mathrm{bc}$ & $42,00 \mathrm{ab}$ & $15,52 \mathrm{c}$ & $19,2 \mathrm{bc}$ & $51,45 a$ \\
\hline 70 & 36,17 a & $47,94 \mathrm{a}$ & $6,93 \mathrm{~b}$ & $25,72 \mathrm{ab}$ & $41,56 \mathrm{ab}$ & $15,23 \mathrm{c}$ & $17,12 \mathrm{bc}$ & $48,12 \mathrm{a}$ \\
\hline 77 & $37,57 \mathrm{a}$ & $47,64 \mathrm{a}$ & $1,43 \mathrm{~b}$ & $34,50 \mathrm{a}$ & $41,17 \mathrm{ab}$ & $15,52 \mathrm{bc}$ & $11,86 \mathrm{c}$ & $48,82 \mathrm{a}$ \\
\hline 84 & $37,57 \mathrm{a}$ & $47,64 \mathrm{a}$ & $1,43 \mathrm{~b}$ & $34,50 \mathrm{a}$ & $41,17 \mathrm{ab}$ & $15,52 \mathrm{bc}$ & $11,86 \mathrm{c}$ & $48,82 \mathrm{a}$ \\
\hline 90 & $37,57 \mathrm{a}$ & $47,64 \mathrm{a}$ & $1,43 \mathrm{~b}$ & $34,50 \mathrm{a}$ & $41,17 \mathrm{ab}$ & $15,52 \mathrm{bc}$ & $11,86 \mathrm{c}$ & $48,82 \mathrm{a}$ \\
\hline
\end{tabular}

Onde: $\mathrm{Cg}=$ Cassia grandis; $\mathrm{Ec}=$ Enterolobium contortisiliquum; $\mathrm{Gu}=$ Guazuma ulmifolia $; \mathrm{Lf}=$ Libidibia ferrea var. leiostachya. As diferentes letras minúsculas indicam que há diferença entre as médias comparando-se as espécies em cada período estudado, para cada tratamento, pelo teste de Tukey ao nível de 5\% de significância.

Foi verificada semelhança estatística entre as médias de plântulas de C. grandis e L. ferrea var. leiostachya provenientes de sementes com tratamento para a superação de dormência, ao longo de toda a série analisada. O mesmo foi notado em G. ulmifolia e $E$. contortisiliquum, que apresentaram os menores valores ao longo do período estudado. Esta última espécie, por sua vez, não se mostrou diferente estatisticamente de $C$. grandis a partir de 77 dias após a emergência.

\section{Discussão}

O comportamento do regime pluviométrico na área ocorreu como registrado por Lundgren et al. (2017), com progressiva redução no volume da precipitação ao longo do período estudado, característico do clima da região. Os valores de temperatura do solo também corresponderam ao esperado, com o seu decréscimo à medida que aumenta a profundidade do solo, condição semelhante ao verificado por Ferreira et al. (2009) e Oliveira (2013). 
Foi observada uma variação gradual dos valores tanto de temperatura como de umidade do solo ao longo do perfil geométrico, conforme visto em Jesus et al. (2017), mostrando que as regiões mais na base do terreno apresentam maiores valores de umidades e menores de temperatura.

A elevada quantidade de água no solo que ocorreu em um curto período de tempo (Figura 1), provocando até mesmo o alagamento das covas onde as sementes foram plantadas, pode ter influenciado as condições de aeração do solo, reduzindo as trocas gasosas por afetar a disponibilidade de oxigênio. Isso pode ter interferido em processos do desenvolvimento das plantas, uma vez que cada espécie responde de forma variada e depende ainda do seu estádio de desenvolvimento (Binotto et al., 2016). Além disso, observou-se acúmulo de solo sobre as sementes, promovido pelo escoamento superficial da água decorrente das chuvas, o que pode ter afetado Cecropia pachystachya tendo em vista o pequeno tamanho de suas sementes, uma vez que não apresentou emergência em campo ao longo de toda a série temporal analisada. Esse acúmulo de solo também foi relatado por Oliveira (2013) em estudo de avaliação de emergência e sobrevivência de plântulas florestais nativas em nascentes do rio Piauitinga, em Salgado, Sergipe.

O maior número de espécies emergidas aumenta uma possível representação de indivíduos estabelecidos. Foi verificado que as sementes das espécies tratadas (Libidibia ferrea var. leiostachya, Cassia grandis e Guazuma ulmifolia) para a superação de dormência apresentaram grande quantidade de plântulas, técnica esta que pode estar relacionada à capacidade em aumentar o recrutamento de algumas espécies, sendo recomendada na atividade de restauração através da semeadura direta (Pereira et al., 2013). Enterolobium contorsiliquum foi a única espécie que não apresentou a mesma resposta para o tratamento de quebra de dormência, que pode ser em decorrência de sensibilidade das sementes ao agente químico sob às condições climáticas que foram submetidas em campo, uma vez que em laboratório esta espécie com o mesmo tratamento para a superação de dormência teve uma taxa média de $86 \%$ de germinação, com $83 \%$ com formação de plântulas normais (Jesus, 2015). Esta situação de aumento de plântulas decorrente da emergência é verificada nas primeiras semanas do estudo, conforme constatado por Jesus et al. (2019), o que pode estar associado à oferta hídrica que promoveu a atividade embrionária, resultando em maior presença de indivíduos para as espécies, que por efeito da mortalidade, vai reduzindo até o final do período analisado.

Em trabalho realizado em trecho de mata ciliar na região do Baixo Rio São Francisco, aplicando-se tratamento para a superação de dormência nas sementes, com algumas espécies utilizadas no presente estudo, Ferreira et al. (2009) observaram taxas superiores de sobrevivência de plântulas para as espécies $L$. ferrea var. leiostachya (87\%), C. grandis (100\%) e E. contortisiliquum (100\%) logo aos 30 dias após a semeadura, com pequena redução nestes valores ao atingir os 90 dias $(75 \%$ e 93\%, para L. ferrea var. leiostachya e $C$. grandis, respectivamente, sendo que E. contortisiliquum manteve a mesma quantidade de indivíduos). Pietro-Souza \& Silva (2014) também obtiveram altos valores de sobrevivência para esta espécie, mas sem emergência para G. ulmifolia em área de preservação permanente localizada no município de Campo Verde, MT.

Analisando o crescimento inicial de espécies florestais em taludes, em trecho de mata ciliar do Rio São Francisco, Holanda et al. (2010) notaram baixa sobrevivência de $C$. grandis, com E. contortisiliquum tendo apenas $11,1 \%$, enquanto a maior sobrevivência foi vista em L. ferrea var. leiostachya, com $40 \%$. Lacerda \& Figueiredo (2009) observaram uma baixa sobrevivência para E. contortisiliquum $(32,4 \%)$ em área de mata ciliar do município de Barra do Corda, MA, com ausência de sobrevivência para G. ulmifolia. Estes autores constataram ainda a influência da distância do leito do rio na sobrevivência das espécies utilizadas, com maior quantidade de indivíduos de $E$. contortisiliquum na porção mais afastada do rio, o que pode influenciar o teor de umidade e condições de temperatura as quais podem ser mais adequadas à esta espécie. Santos et al. (2012) também observaram uma baixa sobrevivência de G. ulmifolia, aos 90 dias após a semeadura, comparandose subsistemas degradados, anteriormente utilizados como pastagem $(11,9 \%)$ e agricultura $(7,2 \%)$, no Campus Rural da Universidade Federal de Sergipe (São Cristóvão, SE), quando as sementes desta espécies foram semeadas sem o uso de protetor físico, o que retrata a sua sensibilidade tanto às condições ambientais como à atuação de insetos (lagartas e formigas). 


\section{Conclusões}

Cassia grandis, Enterolobium contortisiliquum e Guazuma ulmifolia apresentaram comportamento característico de decréscimo na sobrevivência inicial das plântulas com o passar do tempo, em trecho de mata ciliar do Rio Piauitinga, SE, até estabilização após 90 dias, independente das sementes terem ou não recebido tratamento para a superação de dormência. Plântulas de Libidibia ferrea var. leiostachya, sem tratamento para a superação de dormência, apresentaram alta percentagem de emergência e permanência da sobrevivência dos indivíduos emergidos.

\section{Referências}

Azevêdo, S. M. A. de et al. Crescimento de plântulas de jurema preta (Mimosa tenuiflora (Wild) Poiret) em solos de áreas degradadas da caatinga. Engenharia Ambiental, v. 9, n. 3, p. 150-160, 2012.

Binotto, B. et al. Tolerância de plântulas de Cedrela fissilis Vell. a diferentes amplitudes e intensidades de inundação. Ciência Florestal, v. 26, n. 4, p. 1339-1348, 2016. http://dx.doi. org/10.5902/1980509825153.

Brasil. Ministério da Agricultura, Pecuária e Abastecimento. Secretaria de Defesa Agropecuária. Regras para análise de sementes. Brasília, DF, 2009. 399 p.

Cava, M. G. de B. et al. Comparação de técnicas para restauração da vegetação lenhosa de Cerrado em pastagens abandonadas. Hoehnea, v. 43, n. 2, p. 301-315, 2016. http://dx.doi.org/10.1590/2236-8906$18 / 2016$.

Claessen, M. E. C. (Org). Manual de métodos de análise de solo. 2 ed. Rio de Janeiro: EMBRAPA-CNPS, 1997. 212 p. (EMBRAPACNPS. Documentos, 1). Disponível em: http://ainfo.cnptia.embrapa. br/digital/bitstream/item/169149/1/Manual-de-metodos-de-analisede-solo-2-ed-1997.pdf

Costa, M. do P. et al. Avaliação do processo de reabilitação de um trecho de floresta ciliar na Bacia do Rio Itapemirim-ES. Revista Árvore, v. 34, n. 5, p. 835-851, 2010. http://dx.doi.org/10.1590/ S0100-67622010000500009.

Ferreira, D. F. Sisvar: a guide for its bootstrap procedures in multiple comparisons. Ciência e Agrotecnologia, v. 38, n. 2, p. 109-112, 2014. http://dx.doi.org/10.1590/S1413-70542014000200001.

Ferreira, R. A. et al. Semeadura direta com espécies florestais na implantação de mata ciliar no Baixo São Francisco em Sergipe. Scientia Forestalis, v. 37, n. 81, p. 37-46, 2009.

Holanda, F. S. R. et al. Crescimento inicial de espécies florestais na recomposição da mata ciliar em taludes submetidos à técnica da bioengenharia de solos. Ciência Florestal, v. 20, n. 1, p. 157-166, 2010. http://dx.doi.org/10.5902/198050981770.
Jesus, J. B. Estabelecimento de espécies florestais nativas via semeadura direta no rio Piauitinga - Sergipe. 2015. 70 f. Dissertação (Mestrado em Agricultura e Biodiversidade) Universidade Federal de Sergipe, São Cristóvão.

Jesus, J. B. et al. Behavior of the emergence of native forest seedlings for the purpose of recovery of the riparian forest. Revista Floresta, v. 49, n. 1, p. 57-68, 2019. http://dx.doi.org/10.5380/rf.v49i1.56202.

Jesus, J. B. et al. Estabelecimento de espécies florestais nativas via semeadura direta no rio Piauitinga-Sergipe. Floresta e Ambiente, v. 24, 9 p., 2017. http://dx.doi.org/10.1590/2179-8087.028815.

Lacerda, D. M. A. \& Figueiredo, P. S. Restauração de matas ciliares do Rio Mearim no município de Barra do Corda-MA: seleção de espécies e comparação de metodologias de reflorestamento. Acta Amazonica, v. 39, n. 2, p. 295-304, 2009. http://dx.doi.org/10.1590/ S0044-59672009000200008.

Lima, Y. B. C. et al. Germinação de 15 espécies vegetais do cerrado sob diferentes condições de luz. Bioscience Journal, v. 30, n. 6, p. 1864-1872, 2014.

Lundgren, W. J. C. et al. Estimativa pluviométrica através das técnicas da krigagem e cokrigagem no Estado de Sergipe. Revista Brasileira de Geografia Física, v. 10, n. 3, p. 854-865, 2017.

Oliveira, A. S. Semeadura direta e plantio de mudas para recuperação de nascentes no Rio Piauitinga-SE. 2013. $58 \mathrm{f}$. Dissertação (Mestrado em Agroecossistemas) - Universidade Federal de Sergipe, São Cristóvão.

Oliveira-Filho, A. T. et al. Estudos florísticos e fitossociológicos em remanescentes de matas ciliares do Alto e Médio Rio Grande. Belo Horizonte: CEMIG, 1995. 27 p.

Pereira, S. R. et al. Superação de dormência de sementes como estratégia para restauração florestal de pastagem tropical. Pesquisa Agropecuária Brasileira, v. 48, n. 2, p. 148-156, 2013. http://dx.doi. org/10.1590/S0100-204X2013000200004.

Pietro-Souza, W. \& Silva, N. M. da. Plantio manual de muvuca de sementes no contexto da restauração ecológica de áreas de preservação permanente degradadas. Revista Brasileira de Agroecologia, v. 9, n. 3, p. 63-74, 2014.

Santos, P. L. et al. Estabelecimento de espécies florestais nativas por meio de semeadura direta para recuperação de áreas degradadas. Revista Árvore, v. 36, n. 2, p. 237-245, 2012. http://dx.doi. org/10.1590/S0100-67622012000200005.

Sergipe. Secretaria de Estado do Planejamento e da Ciência e Tecnologia. Superintendência de Recursos Hídricos. Atlas digital sobre recursos hídricos Sergipe. Aracaju, 2011. CD-ROM.

Silva, K. de A. et al. Semeadura direta com transposição de serapilheira como metodologia de restauração ecológica. Revista Árvore, v. 39, n. 5, p. 811-820, 2015. http://dx.doi.org/10.1590/010067622015000500004 .

Sousa, I. F. da, et al. Evapotranspiração de referência nos perímetros irrigados do Estado de Sergipe. Revista Brasileira de Engenharia Agrícola e Ambiental, v. 14, n. 6, p. 633-644, 2010.

Turchetto, F. et al. Aspectos eco-fisiológicos limitantes da regeneração natural. Ecologia e Nutrição Florestal, v. 3, n. 1, p. 18-30, 2015. 